\title{
Demographic Study of Gujjars of Delhi: VI. Factors Affecting Fertility, Infant Mortality and Use of BCM
}

\author{
Shweta Dabral and S.L. Malik \\ Department of Anthropology, University of Delhi, Delhi 110 007, India
}

KEYWORDS Fertility. Infant mortality. Use of BCM. Correlation. Stepwise Multivariate Regression Analysis.

\begin{abstract}
Association between various bio-social factors that affect fertility, infant mortality and use of birth control methods was examined among Gujjars of Delhi. The data were collected from 558 households on ever-married women in the age group 15-49 years. Among Gujjars, women's age has the most significant effect on fertility and family planning acceptance; while fertility influences infant mortality the most. Women's education is also an important determinant of these variables. Stepwise multivariate analysis reflects that older women tend to have higher fertility, followed by higher ideal no. of children. Also, fertility further increases with higher infant mortality (that is the next factor affecting it). It is expected that lowering of infant mortality may help in reducing fertility. Among older woman infant mortality is higher. Usage of family planning methods among older women is lower as compared to women who were younger at the time of field survey. There is a decline in usage of BCM with the increase in surviving children, however if the women has higher desire for sons and higher ideal number of children then their acceptance and use decline further.
\end{abstract}

\section{INTRODUCTION}

Reducing fertility and infant mortality are of high priority in national public health objective in India. In today's scenario fertility control is the most important way to check high growth of population. Fertility, infant mortality, and acceptance of fertility control methods are influenced by a variety of interrelated factors such as age at marriage, education and economic status. Lower infant mortality coupled with higher fertility is a strong motivational factor in the acceptance of fertility control measures. As the relative effect of each factor differs from one population to another, it is of interest to study their association and their contribution (singular as well as collective) in the present population of Gujjars.

Bio-social factors such as woman's age, educational level, age at marriage, economic status and religious attitudes have an effect on fertility (RGI-Fertility Survey, 1971; Elamin and Bhuyan, 1999), in addition to, conception control practices and attitudes, (Bhuyan and Ahmed, 1984). Urbanization, in general, leads to modernization and more development, higher literacy, awareness about health care, more contraceptive use, a higher living standard and prevalence of nuclear families, and all these factors play a

Address Correspondence to: Dr. S. L. Malik, Professor, Department of Anthropology, University of Delhi, Delhi 110 00, India

E-mail: slmalik@rediffmail.com significant role in lowering fertility (UN, 1953; De Jong, 1972; NFHS 1998-99, 2002).

In the past two decades there has been an unprecedented increase in the population particularly in the developing countries due to the remarkable fall in mortality. Decline in mortality rates is directly correlated to the massive investments in health, sanitation, water supply, and other associated sectors (Preston, 1978; Kshatriya et al., 1997). Infant mortality rate is a reliable indicator of health status and well being of the children. Besides, it reflects the socioeconomic development of the population. The study of infant mortality is significant, especially because mortality during the first year of life is invariably high for all countries, irrespective of whether the overall levels of mortality are high or low. Infant and child mortality is relatively higher in groups where fertility is higher, i.e., increased mortality is response to high fertility (Chen et al., 1974; Choudhury et al., 1976). Another relationship is also well recognized i.e., high fertility is a biological and behavioural response to high mortality (Preston, 1978). In single terms higher infant mortality tends to higher fertility and vice-a-versa.

Like fertility, infant mortality is also influenced by a number of factors such as parent's education particularly that of mother (Caldwell, 1979; Nag, 1983; Bhasin and Kshatriya, 1990; UN, 1994) and access to medical facilities (UN, 1985; Jain, 1985; Mahadevan, 1989; Suri Babu and Bhasin, 1990; Chachra and Bhasin, 1998c; Bhasin and Nag, 2002c). In rural India, mother's 
education (individual level variable), income (household level variable), and availability of medical facilities and care (community level variable), are major determinants of infant and child mortality (Jain, 1985). Mortality differential by residence imply that infant mortality is lower in urban areas as compared to rural area (SRS, 1992; Ren, 1996) suggesting that rural infant are more prone to deaths than urban infants.

Closely related to fertility is birth control. Birth control in its modern application means the conscious responsible control of conception. Family planning through contraception aims to achieve two main objectives; firstly to have only the desired number of children and secondly to have these children by proper spacing of pregnancies. In India, there has been a considerable increase in the governmental and non-governmental activities for promoting the adoption of family planning through widespread and intensified efforts as well as clinical services being made available to the users of family planning methods. Acceptance of contraception by a couple is governed by various socio-cultural factors, such as religion (NFHS: 1998-99, 2002) and education of husband and wife (Coale, 1965; Berelson, 1976). In India, the states with greater contraceptive use have generally achieved a more advanced state of socioeconomic modernization. This achievement has generated the observed higher levels of motivation.

Mass media plays an important role in promotion and acceptability of contraception (Bhat, 1996; Ramesh et al., 1996). Spousal communication also increases the likelihood of contraceptive use (Lasee and Becker, 1997; Kamal, 1999; Ghosh, 2001). In addition to this, religious affiliation affects the acceptance of sterilization due to behaviour related to childbearing (Chacko, 1988; Goldscheider and Mosher, 1988; Reddy, 1996). Contraceptive prevalence rate is found to be lower among the Muslim and lower caste Hindu women (Gulati, 1996; Bora et al., 1998).

The present paper is last in the series of research articles dealing with various demography aspects of Gujjars of Delhi. In this paper, an attempt has been made to study the impact of various factors on fertility, infant mortality and use of birth control methods among Hindu Gujjars of Delhi. It aims at exploring singular as well as collective relationship between variables that are affected and those that affect them.

\section{MATERIAL AND METHODS}

The present study was conducted among Hindu Gujjars residing in Delhi. A majority of the Gujjars in Delhi are concentrated in the rural areas. Five Gujjar predominated villages selected at random, were visited during different months of the year 2002. They were Fatehpur Beri, Dera, Molarband, Madanpur Khadar and Asola. The data were collected from ever-married Gujjar women aged 15-49 years from a sample of 558 households using interview schedule. (For details see Dabral and Malik, 2004a).

The information was collected for various variables that affect and those get affected. The dependent variables considered for investigative analysis are fertility (Number of live born children per ever married woman), infant mortality (Infant mortality per ever married woman) and use of birth control methods (Use of BCM for currently married woman: sample size $=541)$. The independent variables included in the statistical analyses have been selected keeping in mind their measurable nature and potential influence on population components namely fertility and mortality, besides, use of birth control methods. The various independent variables on which the information was collected are; Number of live births per ever married woman, Number of surviving children, Infant mortality per ever married woman, Current age of woman, Age at effective marriage of woman, Educational level of women, Educational level of husband, Annual per capita income, Age at menarche, Ideal no. of Children, Desired no. of sons, Use of birth control methods, Type of house and Agricultural land holding. Statistical Package for Social Science (SPSS) was used for statistical analysis. The association between the variables was investigated using correlation analysis. Wherever association was found to be significant linear regression equations was also formulated. Besides, further analysis was done using stepwise multivariate regression approach to assess collective influence of the variables.

\section{RESULTS AND DISCUSSION}

Results of the study of association between population components namely fertility and infant mortality besides use of BCM with factors affecting them are presented in following sections namely; (I) Factors affecting fertility, (II) Factors 
affecting infant mortality and (III) Factors affecting use of BCM.

I. Factors Affecting Fertility: Numerous factors affect fertility among Gujjars, such as age of the woman, ideal no. of children, desire no. of sons, age at menarche, infant mortality, type of house, annual per capita income, presence of agricultural land, woman's age at marriage, husband's education, use of birth control methods and woman's education. The relationship is statistically significant in all the cases except annual per capita income of the household (Table 1). Age of woman is the most important factor affecting fertility of Gujjar woman. Number of live births per women increases as the age of woman increases. Age of the woman, ideal no. of children, desire no. of sons, age at menarche, infant mortality and type of house (Table 1) are responsible for increasing fertility (a positive correlation). Table 1 also shows the linear regression equations for the factors that have a significant relationship with fertility.

Conversely, annual per capita income, presence of agricultural land, woman's age at marriage, husband's education, use of birth control methods and woman's education have reducing effect on woman's fertility (Table 1). Educational status of females is the most important variable accounting for fertility decline (Coale, 1965; Ghosh, 1975; Zachariah, 1981; Jolly, 1981; Johnson, 1993). Among Gujjars, fertility decreases as the educational level of the women increases. In India, women with high school and above education have markedly lower average fertility than the less educated (Mandel- baum, 1974). Kerala had set an example, by having high female literacy leading to higher age at marriage and lower fertility (Zachariah, 1981; Caldwell et al., 1984). Late age at marriage results in low fertility, as there is delay in exposure to the risk of conception (Agarwala, 1967; Durch, 1980; Nag, 1982; Pandey and Talwar, 1987; Yadav and Badari, 1997). The results of the present study also reflect that age at marriage has a direct bearing on fertility. Finding of other researchers also reflects that educational level, economic status, desired no. of sons, use of BCM, etc. affects fertility (RGI-fertility survey, 1971; Basu et al., 1988; Bhasin and Kshatriya, 1990; Elamin and Bhuyan, 1999; Bhasin and Nag, 2002b).

Though the relationship with the economic status is non-significant, it is expected to influence fertility negatively (Table 1). Increas-ing income is associated with the appearance of new consumption and opportu-nities. Economic status is a relative term which is community and region specific. It is defined and understood differently in different commu-nities and region. Also, empirical studies on economic status and fertility relationship do not suggest a definite hypothesis. Yet, it is generally agreed that fertility is negatively related to income (Stycos, 1968; Mahadevan, 1989) and especially, to female earnings (Becker, 1981; Schultz, 1985), even as some studies have shown a positive relationship between economic status and fertility (Driver, 1963; Mandelbaum, 1974). The people of lower economic groups tend to have more children for the need of economic support. Also, women of

Table 1: Association of fertility with factors affecting it: Correlation and linear regression analysis

\begin{tabular}{|c|c|c|c|}
\hline \multirow[b]{2}{*}{ Variables } & \multicolumn{3}{|c|}{ Fertility } \\
\hline & Values of correlation & Regress & ion equations \\
\hline Woman's age & $0.761 *$ & Live births $=-2.202$ & +0.174 Woman's age \\
\hline Ideal no. of children & $0.576 *$ & Live births $=-1.028$ & +1.627 Ideal no. of children \\
\hline Desired no. of sons & $0.516 *$ & Live births $=1.241$ & +1.281 Desired no. of sons \\
\hline Woman's education & $-0.478 *$ & Live births $=4.064$ & - 0.195 Woman's education \\
\hline Age at menarche & $0.465 *$ & Live births $=-7.597$ & +0.764 Age at menarche \\
\hline Ever use of BCM & $-0.340 *$ & Live births $=4.818$ & - 1.377 Use of BCM \\
\hline Husband's education & $-0.339 *$ & Live births $=4.355$ & - 0.149 Husband's education \\
\hline Infant mortality & $0.293 *$ & Live births $=2.905$ & +1.302 Infant mortality \\
\hline Woman's age at marriage & $-0.246 *$ & Live births $=8.061$ & - 0.279 Woman's age at marriage \\
\hline Type of house & $0.100 *$ & Live births $=2.604$ & +0.381 Type of house \\
\hline Have Agricultural land & $-0.087 *$ & Live births $=3.653$ & - 0.329 Agricultural land \\
\hline Annual pc income & $-0.054^{\mathrm{e}}$ & & \\
\hline
\end{tabular}

* Significant at $5 \%$ probability level. In these cases regression equations were formulated

${ }^{\text {£ }}$ Non-significant at $5 \%$ probability level 
poorer groups have tendency to bear more children because of higher infant mortality (and therefore these women have shorter lactation and anovulatory periods before becoming fecund again) and consequently need more children to replace the lost ones (Wyon and Gordon, 1971; Mahadevan, 1979).

The results of stepwise multiple regression analysis for fertility reflect that among fertilityrelated independent variables, woman's age, ideal no. of children, infant mortality, woman's education, use of birth control methods, woman's age at marriage and desire no. of sons show statistically significant association (Table 2). Woman's age is the most important variable in determining the level of the fertility, followed by ideal no. of children and infant mortality (Table 2). Among Gujjars woman's age could explain fifty eight percent of the variance in fertility. Additional, six percent of the variance can be explained by adding ideal no. of children. When infant mortality is added, 3.5 percent fertility is further explained. Addition of remaining variables contributes negligibly in explaining variations in fertility.

II. Factors Affecting Infant Mortality: Among Gujjars infant loss per woman, taken as indicator of infant mortality, is associated with a wide variety of bio-social factors such as woman's age, women's education, husband's education, type of house, woman's age at marriage and annual per capita income. Infant deaths results in more number of live births as women try to compensate their loss in order to achieve their desired number of surviving children. Generally, individuals use family planning methods only after achieving a desired number of children. Age of woman, number of live births per ever married women and type of house have positive effect on Infant mortality (Table 3). Woman who have higher infant mortality tend to have higher fertility and vice-a-versa, which is a well established fact (Chen et al., 1974; Choud-hury et al., 1976; Preston, 1978). This is also true for Gujjars under study. Higher fertility could be a mechanism of compensation to achieve desired number of children.

Women's education, husband's education, women's age at marriage and annual per capita income has a negative effect on infant mortality (Table 3). Increase in educational level of husband and wife decreases the chances of infant mortality as educated people have greater awareness about
Table 2: Association of fertility with factors affecting it: stepwise multivariate regression analysis

\begin{tabular}{|c|c|c|}
\hline $\begin{array}{l}\text { Regression } \\
\text { equations }\end{array}$ & $\begin{array}{l}\text { Coefficient } \\
\text { of corre- } \\
\text { lation }\end{array}$ & $\begin{array}{l}\text { Coefficient } \\
\text { of deter- } \\
\text { mination }\end{array}$ \\
\hline $\begin{array}{l}\text { Live births }=-2.202+0.174 \\
\quad \text { Woman's age }\end{array}$ & $0.761 *$ & $0.579 *$ \\
\hline $\begin{array}{l}\text { Live births }=-3.219+0.144 \\
\text { Woman's age }+0.762 \text { Ideal } \\
\text { no. of children }\end{array}$ & $0.797 *$ & $0.635 *$ \\
\hline $\begin{array}{l}\text { Live births }=-3.136+0.139 \\
\text { Woman's age }+0.731 \text { Ideal no. o } \\
\text { children }+0.837 \text { Infant mortality }\end{array}$ & $\begin{array}{l}0.818 * \\
\text { of } \\
\text { ty }\end{array}$ & $0.670 *$ \\
\hline $\begin{array}{l}\text { Live births }=-2.489+0.132 \\
\text { Woman's age }+0.655 \\
\text { Ideal no. of children }+0.809 \\
\text { Infant mortality }-0.044 \\
\text { Woman's education }\end{array}$ & $0.824 *$ & $0.678 *$ \\
\hline $\begin{array}{l}\text { Live births }=-1.778+0.122 \\
\text { Woman's age }+0.679 \\
\text { Ideal no. of children }+0.825 \\
\text { Infant mortality }-0.046 \\
\text { Woman's education }-0.386 \\
\text { Use of BCM }\end{array}$ & $0.828 *$ & $0.686 *$ \\
\hline $\begin{array}{l}\text { Live births }=-0.619+0.121 \\
\text { Woman's age }+0.688 \\
\text { Ideal no. of children }+0.827 \\
\text { Infant mortality }-0.039 \\
\text { Woman's education - } 0.378 \\
\text { Use of BCM - 0.066 } \\
\text { Woman's age at marriage }\end{array}$ & $0.830 *$ & $0.689 *$ \\
\hline $\begin{array}{l}\text { Live births }=-.475+0.122 \\
\text { Woman's age }+0.457 \\
\text { Ideal no. of children }+0.831 \\
\text { Infant mortality }-0.034 \\
\text { Woman's education }-0.383 \\
\text { Use of BCM }-0.064 \\
\text { Woman's age at marriage }+0.24 \\
\text { Desired no. of sons }\end{array}$ & $0.832 *$ & $0.692 *$ \\
\hline
\end{tabular}

* Significant at $5 \%$ probability level

general sanitation, hygiene, nutrition and availability and usage of health services. Educated parents especially mother ensure lower infant mortality by providing adequate care to their infants in terms of hygiene and health services (Caldwell, 1979; Nag, 1983; Bhasin and Kshatriya, 1990; UN, 1994). However, lower child mortality is noticed only beyond primary level of education. Barring few irregularities it is generally agreed that paternal education also have a negative affect on infant mortality (Caldwell, 1979; Nag, 1983; Hobcraft et al., 1984; UN, 1985; Mahadevan, 1989; Chachra and Bhasin, 1998c; Bhasin and Nag, 2002c). Women who marry young tend to have children at a younger age. As they are not physiological mature, this leads to higher infant mortality. Among Gujjars 
income has a negative effect on infant mortality. Low-income group households have lesser resources to combat illness and environmental hazards resulting in higher infant mortality. This association is well documented (Jain, 1985; UN, 1985; Das Gupta, 1990), though not always monotonic.

Live births and woman's age are found to be statistically significant (Table 4). Fertility (no. of live births) is the most important variable in determining the level of the infant mortality, followed by woman's age. About nine percent of the variance in infant mortality could be explained by fertility of the woman (Table 4). Woman's age could explain around two percent of the variation in infant mortality.

III. Factors Affecting Use of Birth Control Methods: Factors like son preference, women's age, literacy, number of living children and number of living sons influence contraceptive use (Gandotra and Das, 1990; Levine et al., 1992; Bora and Jha, 2001). Couples with fewer sons are more likely to continue having more children, besides, have shorter birth intervals and are also less probable to use contraception (Das Gupta, 1987; Nag, 1991; Raju and Bhat, 1995). Among
Gujjars usage of family planning methods is associated with a number of factors such as woman's age, woman's education, woman's age at marriage, ideal number of children and surviving no. of children. Usage of family planning methods increases with the education of the woman, woman's age at marriage and education of the husband (Table 5). Thus, education of women and that of her husband plays an important role in the adoption of family planning methods. Higher educated women have a better knowledge to use non-terminal method more effectively (Bumpass, 1987). Acceptance of sterilization, which is a terminal birth control method, is influenced by the number of living children in addition to the number of sons and is usually accepted when the couples are sure that they have completed with their family size and gender preference (Khan, 1980; Rajaram, 1998, Das and Acharya, 1999; Rajaretnam, 2000). Among Gujjars sterilization is the most popular birth control method, and it is expected that family size and gender preference plays a role in acceptance of sterilization.

Usage of family planning methods decreases with woman's age, surviving number of children

Table 3: Association of infant mortality with factors affecting it: correlation and linear regression analysis

\begin{tabular}{lccc}
\hline \multicolumn{3}{c}{ Infant Mortality } & \\
\hline Variables & Values of correlation & Regression equations \\
\hline Live births & $0.293^{*}$ & Infant mortality $=$ & $-5.550 \mathrm{E}-02+6.592 \mathrm{E}-02$ Live births \\
Woman's age & $0.126^{*}$ & Infant mortality $=$ & $-4.860 \mathrm{E}-02+6.464 \mathrm{E}-03$ Woman's age \\
Woman's education & $-0.124^{*}$ & Infant mortality $=$ & $0.205 \quad-1.132 \mathrm{E}-02$ Woman's \\
& $-0.079^{\mathrm{f}}$ & & \\
Husband's education & $0.041^{\mathrm{f}}$ & & \\
Type of house & $-0.032^{\mathrm{f}}$ & & \\
Woman's age at marriage & $-0.001^{\mathrm{f}}$ & & \\
Annual pc income & & & \\
\hline
\end{tabular}

* Significant at $5 \%$ probability level. In these case regression equations were formulated

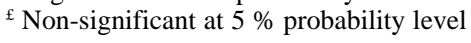

Table 4: Association of infant mortality with factors affecting it: stepwise multivariate regression analysis

\begin{tabular}{lcc}
\hline Regression equations & $\begin{array}{c}\text { Coefficient } \\
\text { of corre- } \\
\text { lation }\end{array}$ & $\begin{array}{c}\text { Coefficient } \\
\text { of deter- } \\
\text { mination }\end{array}$ \\
\hline Infant mortality = & & \\
$\quad-0.056+0.066$ Live births & $0.293 *$ & $0.086 *$ \\
Infant mortality $=$ & $0.329^{*}$ & $0.108^{*}$ \\
$\quad-0.183+0.105$ Live births -0.012 & \\
$\quad$ Woman's age & & \\
\hline
\end{tabular}

* Significant at $5 \%$ probability level and ideal no. of children, besides, desired no. of sons and annual per capita income. Association of use of BCM with variables namely woman's age, surviving no. of children, woman's education, woman's age at marriage, and ideal no. of children is statistically significant. Among Gujjar women who are younger and have lesser number of children appear to be more willing to use contraception as compared to women who are older and have more children. Couples at a higher income level are more likely to use contraceptives. Similar findings have been 
reported among various castes and tribal groups of Uttar Pradesh and Jammu Kashmir (Chachra and Bhasin, 1998e; Bhasin and Nag, 2002d).

Stepwise multivariate regression analysis reflects that the association of usage of family planning methods with woman's age, surviving number of children and ideal number of children is statistically significant (Table 6). The most important variable in determining the level of use of birth control methods among Gujjars is woman's age followed by surviving no. of children and ideal number of children. About 17 percent of the variance in use of BCM could be explained by woman's age (Table 6). Addition of surviving no. of children and ideal number of childrena contribute for smaller proportion of variance.

\section{CONCLUSIONS}

From the foregoing discussion it may be concluded that among Gujjars, woman's age has most significant effect on fertility as well as use of birth control methods while infant mortality is chiefly influenced by fertility. Higher fertility is associated with older women, which increases with the addition of higher ideal no of children and if the infant mortality is higher. Incase of infant mortality, it is expected that if infant mortality is lowered than it may facilitate fertility reduction. Conversely, infant mortality increases as the women grow older. Acceptance and use of family planning methods among older women is lower, perhaps during their active reproductive period they were less aware and less receptive for family planning. The likelihood for usage of birth control methods declines with the increase in surviving children, however, it further declines if the women have higher desire for sons.

Fertility, infant mortality and use of birth control methods, thus, influence each other. Higher fertility is a biological and behavioral response to higher mortality. If there is a mortality decline it is eventually followed by a fertility

Table 5: Association of use of birth control methods and factors affecting it: correlation and linear regression analysis

\begin{tabular}{lcc}
\hline & Use of BCM \\
\hline Variable & Values of correlation & Regression equations \\
\hline Woman's age & $-0.409^{*}$ & Use of BCM $=1.946-0.023$ Woman's age \\
Surviving children & $-0.389^{*}$ & Use of BCM $=1.543-0.105$ Surviving children \\
Woman's education & $0.146^{*}$ & Use of BCM $=1.169+0.015$ Woman's education \\
Woman's age at marriage & $0.115^{*}$ & Use of BCM $=0.673+0.032$ Woman's age at marriage \\
Ideal no. of children & $-0.113^{*}$ & Use of BCM $=1.441-0.079$ Ideal no. of children \\
Type of house & $0.076^{\ddagger}$ & \\
Desired no. of sons & $-0.069^{\ddagger}$ & \\
Have Agricultural land & $0.067^{\ddagger}$ & \\
Annual pc income & $-0.065^{\ddagger}$ & \\
Husband's education & $0.051^{\ddagger}$ & \\
\hline
\end{tabular}

* Significant at $5 \%$ probability level. In these case regression equations were formulated

${ }^{£}$ Non-significant at $5 \%$ probability level

Table 6: Association of use of BCM with factors affecting it: stepwise multivariate regression analysis

\begin{tabular}{lcc}
\hline $\begin{array}{l}\text { Regression } \\
\text { equations }\end{array}$ & $\begin{array}{c}\text { Coefficient of } \\
\text { correlation }\end{array}$ & $\begin{array}{c}\text { Coefficient of } \\
\text { determination }\end{array}$ \\
\hline $\begin{array}{l}\text { Use of BCM = 1.946- } 0.023 \\
\text { Woman's age }\end{array}$ & $0.409 *$ & $0.168 *$ \\
$\begin{array}{l}\text { Use of BCM = 1.847 - } 0.015 \\
\text { Woman's age - } 0.005\end{array}$ & $0.427 *$ & $0.182 *$ \\
$\quad \begin{array}{l}\text { Surviving no. of children } \\
\text { Use of BCM = 1.634 - } 0.017 \\
\quad \text { Woman's age - } 0.073\end{array}$ & $0.452 *$ & $0.204 *$ \\
$\quad \begin{array}{l}\text { Surviving no. of children } \\
+0.126 \text { Ideal No. of Children }\end{array}$ & \\
\hline
\end{tabular}

* Significant at $5 \%$ probability level decline. Higher infant mortality tends to increase fertility as women try to replace their lost children; in order to achieve desired family size. Once the desired number of children and gender composition are achieved, only then women intend to use family planning methods. Lower infant mortality together with higher fertility is a favourable motivating factor in the acceptance of fertility control measures by the couple. Couples don't control child birth, until they are convinced that their infants would not die, though other bio-social variables also influence their reproductive behavior. The present study has been able to separate out to some extent, most important factors influencing fertility, infant 
mortality and use of BCM among Gujjars of Delhi. Thus, the study could be helpful in dealing with these population variables that shape their demographic profile.

\section{ACKNOWLEDGEMENT}

The authors express their profound appreciation for the Gujjars families residing in the villages of Delhi, who form the basis of present study, for their tremendous co-operation and kind help.

\section{REFERENCES}

Agarwala, S.N.: Effect of a rise in female age at marriage on birth rate in India, In: Proceedings of the World Population Conference, Belgrade (1967).

Basu, S.K., Kshatriya, G.K and Jindal, A.: Fertility and mortality differentials among the tribal population groups of among the tribal population groups of Bastar district Madhya Pradesh. Human Biology, 60: 407-416 (1988).

Becker, G.S.: A Treatise on the Family. Harvard University Press, Massachusetts (1981).

Berelson, B.: Social science research on population. Population Development Review, 2: 219-266 (1976).

Bhasin, M.K and Nag, S: A demographic profile of Jammu and Kashmir: Estimates, trends and differentials in mortality. Journal of Human Ecology, 13: 113-140 (2002c).

Bhasin, M.K and Nag, S: A demographic profile of Jammu and Kashmir: Family planning. Journal of Human Ecology, 13: 147-166 (2002d).

Bhasin, M.K and Nag, Shampa: A demographic profile of Jammu and Kashmir: Estimates, trends and differential in fertility behaviour. Journal of Human Ecology, 13: 57-112 (2002b)

Bhasin, M.K. and Kshatriya, G.: Fertility and mortality differentials among the different population groups of Sikkim, India. Journal of Human Ecology, 1:267-276 (1990).

Bhat, P.N. Mari: 'Contours of fertility decline in India: A district level study based on the 1991 Census', In: Population Policy and Reproductive Health K.Srinivasan (Ed.). Hindustan Publications, New Delhi (1996).

Bhuyan, K.C. and Ahmed, M.U.: Fertility and family planning practices in rural Bangladesh. The Journal of Family Welfare, 30(3): 57-70 (1984).

Bora, R.S. and Jha, M.S.: Factors influencing the use of contraception: A study of rural Delhi. Demography India, 30(2): 299-311 (2001).

Bora, R.S., Malik, P. and Kulkarni, V.: 'Operation research on spacing methods: A comparative study for rural Delhi'. Report submitted to the Ministry of Health and Family Welfare, GOI (1998).

Bumpass, L.L.: The risk of an unwanted birth: The changing context of contraceptive sterilization in the US. Population Studies, 41: 347-363 (1987).

Caldwell, J.C., Reddy, P.H. and Caldwell, P.: Determinants of fertility decline in rural South India, In: India's Demography - Essays on the Contemporary Population, T. Dyson and N. Crook (Eds.). South Asian Publications, New Delhi (1984).

Caldwell, J.C.: Education as a factor in mortality decline: An examination of Nigerian data. Population Studies, 33: 395-413 (1979).

Chachra, S.P and Bhasin, M.K: Anthropo-demographic study among the caste and tribal groups of central Himalayas. Journal of Human Ecology, 9: 431-439 (1998c).

Chachra, S.P and Bhasin, M.K: Anthropo-demographic study among the caste and tribal groups of central Himalayas. Journal of Human Ecology, 9: 445-450 (1998e).

Chacko, C.K.: Fertility and Contraceptive Practice among Religious Minorities in Two Districts of Tamilnadu, Research Compendium: Findings and Implications of Population and Health Studies, 1964-87. The Gandhigram Institute of Rural Health and Family welfare Trust, Gandhigram, Tamilnadu (1988).

Chen, L.S., Ahmed, M.G. and Mosley, W.H.: A prospective study of birth interval dynamics in rural Bangladesh. Population Studies, 28(2): 277-279 (1974).

Choudhury, R.H., Khan, A.R. and Chen, L.S.: The effect of child mortality experience on subsequent fertility: Pakistan and Bangladesh. Population Studies, 30(2): 249-262 (1976)

Coale, A.J.: Factors associated with the developing of low fertility: A historic summary, In: Proceedings of the World Population conference, Vol. II: 205-229 (1965).

Dabral, S. and Malik, S.L.: Demographics study of Gujjars of Delhi: I. Population structure and socio-cultural profile. Journal of Human Ecology, 16: 17-24 (2004a).

Das Gupta, M.: Death clustering, mother's education and the determinants of child mortality in rural Punjab, India. Population studies, 44: 489-505 (1990).

Das Gupta, M.: Selective discrimination against female children in rural Punjab, India. Population and Development Review, 13: 77-100 (1987).

Das, M. and Acharya, S.: Correlates of female decisionmaking in an urban Indian society. Journal of Family Welfare, 45(2): 30-42 (1999).

De Jong, G.F.: Patterns of human fertility. In: The Structure of Human Populations, G.A. Harrison and A.J. Boyce (Eds.). Clarendon Press, Oxford (1972).

Driver, E.D. (1963): Fertility Differentials in Central India. Princeton University Press, Princeton.

Durch, J.A.: Nuptiality Patterns in Developing Countries Implications of Fertility. Population Reference Bureau, Washington (1980)

Elamin,M.A and Bhuyan,K.C. : Differential fertility in North Eastern Libya. The Journal of Family Welfare, 45(1):1222 (1999).

Gandotra, M.M. and Das, N.P.: Contraceptive choice, shift and use continuation: A prospective study. Journal of Family Welfare, 36(3): 54-69 (1990).

Ghosh, B.: Recent studies in social and economic determinants of fertility: A review and a critique. Journal of Family Welfare, 21: 38-45 (1975).

Ghosh, Rima: Intention not to use contraception: A comparative study of Northern and Southern states of India. Demography India, 30(2): 261-280 (2001).

Goldscheider, C. and Mosher, W.D.: Religious affiliation and contraceptive usage: changing American patterns, 195182. Studies in Family Planning, 19: 48-57 (1988).

Gulati, S.C.: Contraceptive method's use and choice in Kerala 
and Uttar Pradesh: multinomial logit analysis of NFHS data. Demography India, 25(1): 205-220 (1996).

Hobcraft, J.N., McDonald, J.W. and Rustein, S.O.: Socioeconomic factors in infant and child mortality: A cross-national comparison. Population Studies, 38:193223 (1984).

Jain, A.K.: Determinants of regional variations in infant mortality in rural India. Population Studies, 39:407424 (1985).

Johnson, N.E.: A test of three hypotheses. Social Biology, 40: 87-105 (1993).

Jolly, K.G.: Differential fertility performance by education, age at marriage and work status of women in Delhi metropolis. Demography India, 10: 118-125 (1981).

Kamal, N.: Inter-spousal communication on family planning as a determinant of the use of modern conception in Bangladesh. Journal of Family Welfare, 45(1): 31-43 (1999).

Khan, M.E.: Determinants of sterilization in India. In: The Role of Surveys in the Analysis of Family Planning Programmes, A.I. Hermalin and B. Entawilse (Eds.). Oridna Publications, Belgium (1980).

Kshatriya, G.K., Singh, P. and Basu, S.K.: Anthropodemographic features and health care practices among the Jaunsaris of Jaunsar-Bawar, Dehradun, Uttar Pradesh. Journal of Human Ecology, 8: 347-354 (1997).

Lasee, A. and Becker, S.: Husband-wife communication about family planning and contraceptive use in Kenya. International Family Planning Perspectives, 23(1): 1520 (1997).

Levine, R.E., Cross, H.E., Chhabra, S. and Viswanathan, H.: Quality of health and family planning services in rural Uttar Pradesh: The client's view. Demography India, 21(2): 247-265 (1992).

Mahadevan, K.: Population Dynamics in Indian States: Fertility and Family Formation and Mortality and Life Affecting Variables. Mittal Publications, New Delhi (1989).

Mahadevan, K.: Sociology of Fertility: Determinants of Fertility Differentials in South India. Sterling Publishers, New Delhi (1979).

Mandelbaum, D.G.: Human fertility in India: Social Components and Policy Perspectives. University of California Press, Berkeley (1974).

Nag, M.: Impacts of social development and economic development on mortality: Comparative study of Kerala and West Bengal. Economic and Political Weekly, 18: 877-900 (1983)

Nag, M.: Modernization and its Impact on Fertility: The Indian Scene. The population Council, New York (1982).

Nag, M.: Sex preference in Bangladesh, India and Pakistan and its effect on fertility. Demography India, 20: 163 185 (1991).

National Family Health Survey (NFHS), 1998-99, Delhi: International Institute of Population Sciences, Mumbai (2002).

Pandey, G.D. and Talwar, P.P.: Some aspects of marriage and fertility in rural Uttar Pradesh. Demography India, 16: 301-310 (1987)

Preston, H. Samuel: The Effects of Infant and Child Mortality on Fertility. Academic Press, New York (1978).

Rajaram, S.: Timing of sterilization in two low fertility states in India. Demography India, 27: 179-191 (1998).

Rajaretnam, T.: Socio-cultural determinants of contraceptive method choice in Goa and Kerala, India. Journal of Family Welfare, 46(2): 1-11 (2000).

Raju, K.N.M. and T.N. Bhat: Sex composition of living children against socio-economic variables while accepting family planning methods. Demography India, 24: 87-99 (1995)

Ramesh, B.M., Gulati, S.C. and Rutherford, Robert D.: Contraceptive use in India. National Family Health Survey Subject Reports No. 2. IIPS, Mumbai and Honolulu, East-West Center (1996).

Reddy, M.M.K.: Fertility and Family Planning Behaviour in Indian Society. Kanishka Publishers and Distributors, New Delhi (1996).

Registrar General and Census Commissioner, India (RGI) Fertility Differentials in India. Office of Registrar General, New Delhi (1971).

Ren, X.S.: Regional variation in infant survival in China. Social Biology, 43: 1-19 (1996).

Schultz, T.P.: Changing world prices, women's wages, and the fertility transition: Sweden, 1860-1910. J. Political Econ., 98:1126-1154 (1985).

SRS: Sample Registration system, fertility and mortality indicators. Office of Registrar General, New Delhi (1992).

Stycos, J.M.: Social class and differential fertility in Peru. In: Population and Society, C.Nam (Ed). Houghton Mifflin Co. Boston (1968).

Suri Babu, K. and Bhasin, M.K: Mortality differentials among occupationally different communites: Yadava and Kamma in Andhra Pradesh. Journal of Human Ecology, 1:185-187 (1990).

United Nations: Determinants Consequences of Population Trends, Population Studies No.17.United Nations, New York (1953).

United Nations: Socioeconomic Differentials in Child Mortality in Developing Countries. United Nations, New York (1985).

United Nations: The Health Rationale for Family Planning; Timing of Births and Child Survival. United Nations, New York (1994).

Wyon, John .B. and Gordon, John. B.: The Khanna Study: Population problems in the rural Punjab. Cambridge University Press, Cambridge (1971).

Yadav, S.S. and Badari, V.S.: Age at effective marriage and fertility: An analysis of data for North Kanara. The Journal of Family Welfare, 43(3): 61-66 (1997).

Zachariah, K.C.: Anomaly of the Fertility Decline in Kerala: Social Change, Agrarian Reform of the Family Planning Programme? Population and Human Resources Division, Discussion Paper, No. 8:1-17, World Bank, Washington (1981). 